\title{
IRON DEFICIENCY - CONSEQUENCES AND EVALUATION MARKERS
}

\author{
Anelia Bivolarska ${ }^{1}$, Nadia Jekova ${ }^{2}$, Iliyan Dimitrov ${ }^{1}$ \\ ${ }^{1}$ Department of Chemistry and Biochemistry, Faculty of Pharmacy, \\ Medical University - Plovdiv \\ ${ }^{2}$ Medical Student, Medical University - Plovdiv
}

\begin{abstract}
Iron deficiency is particularly common among risk population groups such as children, adolescents, pregnant and lactating women, as well as elderly people. The concentration of serum ferritin (SF) is proportional to the size of the iron stores of the body in healthy individuals and those with early iron deficiency. When the SF concentration falls below $15 \mu \mathrm{g} / \mathrm{L}$, the iron stores are totally depleted. An increased total iron-binding capacity $(>400 \mu \mathrm{g} / \mathrm{dL})$ is therefore indicative of iron storage depletion. It is less precise than the SF concentration. During iron deficiency the participation of iron in heme formation is reduced, which leads to a gradual accumulation of protoporphyrin. The serum transferrin receptor (sTfR) is a more sensitive indicator of iron deficiency. The elevated sTfR is the first laboratory criterion of iron deficiency after the depletion of the iron stores in the organism and its increase continues in direct proportion to the severity of the iron deficiency. Each evaluation of the iron status should include the $\mathrm{Hb}$ concentration, since it is indicative of a more advanced stage of iron deficiency. There are significant correlation dependencies $(p<0.05)$ between the different indicators of iron homeostasis (sTfR, SF and $\mathrm{Hb}$ ).
\end{abstract}

Keywords: iron deficiency, serum ferritin, serum transferrin receptor, hemoglobin, protoporphyrin

\section{Iron Metabolism}

Iron is an essential trace element, located within each cell, the bulk of which is found in the erythrocytes. Erythrocytes are produced in the bone marrow and after a 120-day long lifespan they are destroyed in the spleen where iron is released. Most of the iron, used for the production of new erythrocytes, comes from the breakdown of old erythrocytes and only a small portion of it is derived from the iron obtained through the digested food (19). A large part

\footnotetext{
Address for correspondence:

Anelia Bivolarska

Medical University - Plovdiv

Department of Chemistry and Biochemistry

15 A Vassil Aprilov Blvd.

4002 Plovdiv, BULGARIA

e-mail:anellena@abv.bg
}

Received: November 23, 2015

Accepted: February 5, 2016 of the iron is being released with the exfoliated enterocytes, skin cell and urine. Additional losses are observed during the menstrual blood loss in females. The iron metabolism differs from the one of other minerals and trace elements in that its release from organism cannot be controlled in contrast to its absorption (20).

Theoretically, when the organism needs more iron, its absorption is increased, while, when the iron is sufficient, the absorption is limited (22). Iron is absorbed mainly in the duodenum via an active process, through which, from the intestinal lumen, iron enters the mucous cell, from where it is being transported to the blood, when necessary (10). If the organism does not need iron, it is stored as ferritin in the intestinal cell. Two factors are considered to take part in controlling the iron absorption: the size of the iron stores, as well as the erythropoietic activity (17). Erythroid regulation is activated mainly when the 
bone marrow suffers an acute need of iron, while the regulation of iron stores is responsible from maintaining the iron balance through iron absorption control (20).

The peptide hormone hepcidin is a negative regulator of iron metabolism, which inhibits iron transportation by binding with the iron channel ferroportin, residing in the enterocytes and the reticuloendothelial cells. It influences the iron mobilization by the liver and spleen, as well as the transplacental iron transfer during pregnancy (32).

\section{CONSEQUENCES OF IRON DEFICIENCY}

\section{Cognitive Development}

There is strong evidence that IDA (Iron Deficiency Anemia), during the first few years of life, is associated with abnormal cognitive and motor development, as well as with behavioral issues. Longitudinal studies consistently show that children, who were anemic in early childhood, continue to have poor cognitive and motor development, plus unsatisfactory performance in school as well (18). Iron deficiency has been found in children suffering from attention deficit disorder. Iron concentration in the umbilical artery is of critical importance during fetal development and is related to the IQ (Intelligence Quotient) of the child. Iron deficiency anemia is common, especially in females, and is associated with manifestations of apathy, depression and rapid onset fatigue during physical activity (7).

IDA in infancy and early childhood is not likely to be corrected by a subsequent iron therapy (36). Grantham-McGrego, Ani (2001) have researched the effect of iron supplementation on the cognitive development of children over 2 years of age and have reached the conclusion that iron therapy has a beneficial effect in older anemic children. In four studies with children iron therapy has had a positive effect; in other three studies the benefit was highly probable, while two studies show it has no effect whatsoever. In children under 2 years of age the casual connection is controversial (18). However, according to the authors of this article, the results of many studies are difficult to construe, since the size of the studied groups is not large enough so as to lead to a reliable interpretation of the data.

Experimental studies with rats demonstrate that in different stages of life, various parts of the brain contain high concentration of iron. The aforementioned studies show that iron deficiency in the brain depends on the period during which iron deficiency occurs (29).

\section{Impact of IDA on the Immune System}

Most pathogens need iron and other trace elements, and thus have developed complex mechanisms for acquiring them. Iron is required by the host for the modulation of an effective immune response as well (2). Experimental and clinical studies suggest an increased risk of infection during an existing iron deficiency, even though a small number of scientific reports state the opposite (2). The difficult interpretation of many studies derives from the existence of additional circumstances such as poverty, malnutrition and multiple micronutrient deficiencies, as well as the presence of infection (12). Nevertheless, based on a review of 13 random clinical trials, the International Nutritional Anemia Consultative Group (23), states that known benefits of iron supplementation are likely to outweigh the risk of adverse effects in regions with endemic malaria. In a random clinical study conducted in Tanzania, infants with malaria have been treated with Sulphadoxine-pyrimethamine or placebo. Those, who received iron supplements, were between 2 and 6 months of age. During the first year of their lives clinical malaria has been reduced by $59 \%$, while the instances of severe anemia have been reduced by $50 \%$ in the treated group, as opposed to the placebo group (31), which demonstrates a significant impact of malaria on the anemic onset.

A study, conducted on Turkish children, confirms that iron deficiency influences the humoral-, cell- and non-specific immunity, as well as the cytokine activity, which plays a key role in different stages of the immune mechanisms (15).

Changes in Metabolism during Iron Deficiency

Many metabolic processes change during iron deficiency. The activity or concentration of various iron-containing enzymes in skeletal muscles and liver are being decreased during IDA (11). The concentration of the main regulators of glucose synthesis - the catecholamines epinephrine and norepinephrine, deviates from the norm in humans and rats with iron deficiency (26). 
Anelia Bivolarska, Nadia Jekova, Iliyan Dimitrov

Iron deficiency influences the neurotransmitter system as well. Beard (2001), points out that the dopaminergic system, which is the main mediating system of the central nervous system, is extremely sensitive to changes of the iron status. There is evidence that serotonin and norepinephrine metabolism in rats also change during iron deficiency (28).

One of the main effects of chronic iron deficiency on the circulatory system is cardiac hypertrophy (27). It is assumed that myocardial hypertrophy is physiological, aiming at maintaining the oxygen supply to peripheral tissues in anemic animals (33).

Some of the undesired side effects of iron deficiency may be attributed to the presence of anemia, while others are more directly related to the decrease of iron in the organism, as well as to limitations in the tissue oxygen capacity (4). Nevertheless, differentiating the after effects of decreased oxygen transportation from iron deficiency in tissues is difficult, because tissue iron deficiency occurs simultaneously with the decrease of oxygen transportation in humans with IDA (2).

\section{Biochemical Indicators for Iron Deficiency}

\section{Evaluation}

A series of laboratory indicators can be used to characterize iron status precisely and to categorize the severity of iron deficiency. Three levels of iron deficiency are customarily identified:

* depleted iron stores, but where there appears to be no limitation in the supply of iron to the functional compartment;

* early functional iron deficiency (iron-deficient erythropoiesis) where the supply of iron to the functional compartment is suboptimal but not reduced sufficiently to cause measurable anemia; and

* iron deficiency anemia, where there is a measurable deficit in the most accessible functional compartment, the erythrocyte (14).

\section{STORAGE IRON DEPLETION}

\section{Serum Ferritin Concentration.}

Cellular iron, which is not immediately needed for functional compounds, is stored in the form of ferritin. Small quantities of ferritin also circulate in the blood. The concentration of plasma and serum ferritin is proportional to the size of body iron stores in healthy individuals and those with early iron deficiency. In an adult, each $1 \mu \mathrm{g} / \mathrm{L}$ of serum ferritin indicates the presence of about $8 \mathrm{mg}$ of storage iron (6). A similar relationship is present in children in that each $1 \mu \mathrm{g} / \mathrm{L}$ of serum ferritin is indicative of an iron store of about $0.14 \mathrm{mg} / \mathrm{kg}(16)$. When the serum ferritin concentration falls below $15 \mu \mathrm{g} / \mathrm{L}$, the iron stores are totally depleted (36).

Serum ferritin concentrations are known to be affected by factors other than the size of iron stores. The concentrations are increased in the presence of infections, inflammatory disorders, cancers, and liver disease because ferritin is an acute phase protein (35). Thus, serum ferritin concentration may fall within the normal range in individuals who have no iron stores. It is increased during alcohol intake and hyperglycemia as well, and is directly related to the body mass index (BMI) (21).

Despite the influence of various unrelated factors on serum ferritin concentration, this indicator is the most sensitive one for the amount of iron in the storage compartment.

\section{Total Iron-Binding Capacity}

Iron is transported in the plasma and extracellular fluid bound to transferrin. This metalloprotein has a very high affinity for iron. Virtually all plasma iron is bound to transferrin. Therefore it is convenient to measure plasma transferrin concentration indirectly by quantifying the total iron-binding capacity (TIBC), which is the total quantity of iron bound to transferrin after the addition of exogenous iron to plasma. TIBC is elevated with iron storage depletion before there is evidence of inadequate delivery of iron to erythropoetic tissue. An increased TIBC ( $>400 \mu \mathrm{g} / \mathrm{dL})$ is therefore indicative of storage iron depletion. It is less precise than the serum ferritin concentration. About 30 to 40 percent of individuals with iron deficiency anemia have TIBCs that are not elevated (30). TIBC is reduced during infectious, inflammatory, or neoplastic disorders (25).

\section{Early Iron Deficiency}

Early iron deficiency is signaled by evidence indicating that the iron supply to the bone marrow and other tissues is only marginally adequate. A measurable decrease in the hemoglobin concentration is not yet present and therefore there is no anemia (14). 


\section{Serum Transferrin Saturation}

As the iron supply decreases, the serum iron concentration falls and the saturation of transferrin is decreased. Levels below 16 percent saturation indicate that the rate of delivery of iron is insufficient to maintain the normal rate of hemoglobin synthesis. Low saturation levels are not specific for iron deficiency and are encountered in other conditions such as anemia of chronic disease (13), which is associated with impaired release of iron from stores.

\section{Erythrocyte Protoporphyrin Concentration}

Heme is formed in developing erythrocytes by the incorporation of iron into protoporphyrin IX by ferrochetalase. If there is insufficient iron for optimal hemoglobin synthesis, erythrocytes accumulate an excess of protoporphyrin, which remains in the cells for the duration of their lifespans (13). An increased erythrocyte protoporphyrin concentration in the blood therefore indicates that the erythrocytes matured at a time when the iron supply was suboptimal. The cut off concentration for erythrocyte protoporphyrin concentration is greater than $70 \mu \mathrm{g} / \mathrm{dL}$ of erythrocytes (8).

Soluble Serum Transferrin Receptor
Concentration

The surfaces of all cells express transferrin receptors in proportion to their requirement for iron. A truncated form of the extracellular component of the transferrin receptor is produced by proteolytic cleavage and released into the plasma in direct proportion to the number of receptors expressed on the surfaces of body tissues. As functional iron depletion occurs, more transferrin receptors appear on cell surfaces. The concentration of proteolytically cleaved extracellular domains, or soluble serum transferrin receptors (sTfR), increases parallel to this. The magnitude of the increase is proportional to the functional iron deficit. The sTfR concentration appears to be a specific and sensitive indicator of early iron deficiency (1). sTfR is not influenced by inflammatory diseases (34).

Because commercial assays for sTfR have become available only recently, there is a lack of data relating iron intake to sTfR concentration, as well as relating sTfR concentration to functional outcomes. This indicator may prove to be very useful in identifying iron deficiency, especially in patients who have concurrent infections or other inflammatory disorders.

\section{Iron Deficiency Anemia}

Anemia is the most easily identifiable indicator of functional iron deficiency. As discussed above, physiological impairment occurs at this stage of iron deficiency both because of inadequate oxygen delivery during exercise and because of abnormal enzyme function in tissues (14).

\section{Hemoglobin Concentration and Hematocrit}

The hemoglobin concentration or hematocrit is neither a sensitive, nor a specific indicator of mild, yet functionally significant, iron deficiency anemia. Iron deficiency anemia is microcytic (reduced mean erythrocyte volume and mean erythrocyte hemoglobin). However, microcytic anemia is characteristic of all anemias in which the primary abnormality is impaired hemoglobin synthesis. Iron deficiency is only one of the potential causal factors. The diagnosis of iron deficiency anemia, based solely on the presence of anemia, can result in misdiagnosis in many cases (14).

\section{Erythrocyte Indexes}

Iron deficiency leads to the formation of small erythrocytes. Mean corpuscular hemoglobin $(\mathrm{MCH})$ is the amount of hemoglobin in erythrocytes. The mean corpuscular volume (MCV) is the volume of the average erythrocyte. Both $\mathrm{MCH}$ and MCV are reduced in iron deficiency, but their values are not specific for it. They occur in all conditions that cause impaired hemoglobin synthesis, particularly the thalassemias (9).

Iron deficiency is particularly common among risk population groups such as children, adolescents, pregnant and lactating women, as well as elderly people.

Our studies on pregnant women demonstrate that ferritin in $69 \%$ of them is below $15 \mu \mathrm{g} / \mathrm{L}$, with the highest percentage in the third trimester, while hemoglobin in $36.7 \%$ of them is below $110 \mathrm{~g} / \mathrm{L}$ (4) - a criterion for iron deficiency during pregnancy (24).

Results from our studies on pregnant women show significant correlation among the indicators of iron homeostasis: significant negative correlation between sTfR/SF $(\mathrm{R}=-0.460, \mathrm{p}<0.0001)$, sTfR/Hb $(\mathrm{R}=-$ $0.302, \mathrm{p}=0.002$ ), and a positive one between $\mathrm{Hb} / \mathrm{SF}$ $(\mathrm{R}=0.389, \mathrm{p}<0.0001)$ as compared to the controls, in 
Anelia Bivolarska, Nadia Jekova, Iliyan Dimitrov

which those dependencies are lost ( $p>0.05)$. The gestation period has a significant impact on the level of all iron indicators with a lowering of $\mathrm{Hb}$ and $\mathrm{SF}$ and elevation of sTfR during pregnancy (3).

These results reflect the increased iron needs in relation to nutrition and fetus growth, as well as an iron deficiency tendency, which is most prominent during the last months of pregnancy (3).

\section{CONCLUSION}

Iron deficiency has a wide range of adverse effects on health. While it is not the sole reason for anemic onset, iron deficiency is the most common causal factor for anemia. Iron deficiency develops in three overlapping stages. The three main places where iron resides - the stores, the transported iron and the erythroid iron, are consecutively affected by a rising deficiency of this trace element in the organism. Serum ferritin concentration is considered to be the most practical and sensitive indicator, which correlates with the level of all iron stores in the organism. sTfR is the first laboratory criterion of iron deficiency after the depletion of the iron stores. Hemoglobin determines a more advanced stage of the absence of iron and this is a quantitative measure of the iron deficiency severity, when anemia is already present.

\section{REFERENCES}

1. Akesson A, Bjellerup P, Berglund M, Bremme K, Vahter M. Serum transferrin receptor: A specific marker of iron deficiency in pregnancy. Am J Clin Nutr. 1998;68:1241-1246.

2. Beard JL. Iron biology in immune function, muscle metabolism and neuronal functioning. J Nutr. 2001;131:568S-579S; discussion 580S.

3. Bivolarska A, Iodine and iron deficiency in risk population groups in some regions of southern Bulgaria and the influence of environmental factors on their distribution. $\mathrm{PhD}$ dissertation, Plovdiv, Bulgaria, Medical University - Plovdiv, 2014 (Bulgarian).

4. Bivolarska A, Gatseva P, Maneva A. Association Between Thyroid and Iron Status of Pregnant Women in Southern Bulgaria. J of Endocrinol and Diabetes Mellitus. 2013;1:15-21.

5. Borel MJ, Smith SH, Brigham DE et al. The impact of varying degrees of iron nutriture on several functional consequences of iron deficiency in rats. J Nutr. 1991;121:729-736.
6. Bothwell TH, Charlton RW, Cook JD, Finch CA. 1979. Iron Metabolism in Man. Oxford: Blackwell Scientific.

7. Bourre JM. Effects of nutrients (in food) on the structure and function of the nervous system: update on dietary requirements for brain. Part 1: micronutrients. J Nutr Health Aging. 2006;10(5):377-85.

8. Braun J. Erythrocyte zinc protoporphyrin. Kidney Int Suppl. 1999;69:S57-S60.

9. Chalevelakis G, Tsiroyannis K, Hatziioannou J, Arapakis G. Screening for thalassaemia and/or iron deficiency: Evaluation of some discrimination functions. Scan J Clin Lab Invest. 1984;44:1-6.

10. Charlton RW, Bothwell TH. Iron absorption. Annu Rev Med. 1983;34:55-68.

11. Chen OS, Schalinske KL, Eisenstein RS. Dietary iron intake modulates the activity of iron regulatory proteins and the abundance of ferritin and mitochondrial aconitase in rat liver. J Nutr. 1997;127:238-248.

12. Cook JD, Baynes RD, Skikne BS. Iron deficiency and the measurement of iron status. Nutr Res Rev. 1992;5:189-202.

13. Cook J. The nutritional assessment of iron status. Arch Latinoam Nutr. 1999;49:11S-14S.

14. Dietary reference intakes for Vitamin A, Vitamin $\mathrm{K}$, Arsenic, Boron, Chromium, Copper, Iodine, Iron, Manganese, Molybdenum, Nickel, Silicon, Vanadium, and Zinc. A Report of the Panel on Micronutrients. Institute of Medicine. National academy press. Washington, D.C. 2001.

15. Ekiz C, Agaoglu L, Karakas Z et al. The effect of iron deficiency anemia on the function of the immune system. The Hematol J. 2005;5:579-583.

16. Finch CA, Huebers H. Perspectives in iron metabolism. N Engl J Med. 1982;306:1520-1528.

17. Finch C. Regulators of iron balance in humans. Blood. 1994;84:1697-1702.

18. Grantham-McGregor S, Ani C. A review of studies on the effect of iron deficiency on cognitive development in children. J Nutr. 2001;131:649S-666S; discussion 666S-668S.

19. Hallberg L, Sandström B, Aggett PJ. Iron, zinc and other trace elements. In: Garow JS, James WPT (eds) Human nutrition and dietetics. Edinburgh: Churchill Livingstone. 1993; pp. 174-207. 
20. Hallberg L. Perspectives on nutritional iron deficiency. Annu Rev Nutr. 2001;21:1-21.

21. Hambidge M. Biomarkers of Nutritional Exposure and Nutritional Status. Biomarkers of Trace Mineral Intake and Status. J Nutr. 2003;133:948S-955S.

22. Hurrell R. Iron. In: Hurrell R (eds).The mineral fortification of foods. Surrey: Leatherhead Food RA. 1999;pp. 54-93.

23. INAG (International Nutritional Anemia Consultive Group). Safety of iron supplementation programs in malaria-endemic regions. Washington, DC: ILSI press. 2000.

24. Ivanova I. Strategies for micronutrient deficiencies management. The science of nutrition in the preservation of human health. Edited by Popov B., "Blenda" publishing. Sofia. 2004; 204-213

25. Konijn AM. Iron metabolism in inflammation. Baillieres Clin Haematol. 1994;7:829-849.

26. Martinez-Torres C, Cubeddu L, Dillmann E et al. Effect of exposure to low temperature on normal and iron-deficient subjects. Am J Physiol.1984;246:R380-383.

27. Medeiros DM, Beard JL. Dietary iron deficiency results in cardiac eccentric hypertrophy in rats. P Soc Exp Biol Med. 1998;218:370-375.

28. Morse A, Beard JL, Jones B. Behavioral and neurochemical alterations in iron deficient mice. Proc Soc Exp Biol Med. 1999;220:147-152.

29. Pinero D, Jones B, Beard J. Variations in dietary iron alter behavior in developing rats. J Nutr. 2001;131:311-318.

30. Ravel R. 1989. Clinical Laboratory Medicine: Clinical Application of Laboratory Data. Chicago: Year Book Medical Publishers.

31. Schellenberg D, Menendez C, Kahigwa E et al. Intermittent treatment for malaria and anaemia control at time of routine vaccinations in Tanzanian infants: a randomised, placebo-controlled trial. Lancet. 2001;357:1471-1477.

32. Serap S, Derbent A, Uysal S, Turhan N. Hepcidin, iron status, and inflammation variables among healthy pregnant women in the Turkish population. The Journal of Maternal-Fetal \& Neonatal Medicine. 2013. doi: 10.3109/14767058.2013.804054.

33. Smith SM, Smith SH, Beard JL. Heart norepinephrine content in iron deficiency anemia. P Soc Exp Biol Med. 1990;193:306-312.
34. Staubli Asobayire F, Adou P, Davidsson L et al. Prevalence of iron deficiency with and without concurrent anemia in population groups with high prevalences of malaria and other infections: a study in Côte d'Ivoire. Am J Clin Nutr. 2001;74:776-782.

35. Valberg LS. Plasma ferritin concentration: Their clinical significance and relevance to patient care. Can Med Assoc. 1980;122:1240-1248.

36. $\mathrm{WHO} / \mathrm{UNICEF} /$ United Nations University. Iron deficiency anemia: Assessment, prevention, and control. WHO, Geneva, 2001. WHO/NHD/01.3. 